\title{
Organohalide-respiring Desulfoluna species isolated from marine environments
}

\author{
Peng Peng ${ }^{1} \cdot$ Tobias Goris $\mathbb{1}^{2,11} \cdot$ Yue $\mathrm{Lu}^{3} \cdot$ Bart Nijsse ${ }^{4}$ - Anna Burrichter ${ }^{5,6}$ - David Schleheck ${ }^{5,6}$. \\ Jasper J. Koehorst $\mathbb{1}^{4} \cdot$ Jie Liu $^{7} \cdot$ Detmer Sipkema $^{1}$ - Jaap S. Sinninghe Damste ${ }^{8,9}$ - Alfons J. M. Stams ${ }^{1,10}$. \\ Max M. Häggblom ${ }^{7} \cdot$ Hauke Smidt (i]) ${ }^{1} \cdot$ Siavash Atashgahi $\mathbb{( i D}^{1}$
}

Received: 8 May 2019 / Accepted: 16 December 2019 / Published online: 2 January 2020

(c) The Author(s) 2020. This article is published with open access

\begin{abstract}
The genus Desulfoluna comprises two anaerobic sulfate-reducing strains, D. spongiiphila $\mathrm{AA}^{\mathrm{T}}$ and $D$. butyratoxydans $\mathrm{MSL71}^{\mathrm{T}}$, of which only the former was shown to perform organohalide respiration (OHR). Here we isolated a third strain, designated D. spongiiphila strain DBB, from marine intertidal sediment using 1,4-dibromobenzene and sulfate as the electron acceptors and lactate as the electron donor. Each strain harbors three reductive dehalogenase gene clusters $(r d h A B C)$ and corrinoid biosynthesis genes in their genomes, and dehalogenated brominated but not chlorinated organohalogens. The Desulfoluna strains maintained OHR in the presence of $20 \mathrm{mM}$ sulfate or $20 \mathrm{mM}$ sulfide, which often negatively affect other organohalide-respiring bacteria. Strain DBB sustained OHR with $2 \%$ oxygen in the gas phase, in line with its genetic potential for reactive oxygen species detoxification. Reverse transcription-quantitative PCR revealed differential induction of $r d h A$ genes in strain DBB in response to 1,4-dibromobenzene or 2,6-dibromophenol. Proteomic analysis confirmed expression of $r d h A l$ with 1,4-dibromobenzene, and revealed a partially shared electron transport chain from lactate to 1,4-dibromobenzene and sulfate, which may explain accelerated OHR during concurrent sulfate reduction. Versatility in using electron donors, de novo corrinoid biosynthesis, resistance to sulfate, sulfide and oxygen, and concurrent sulfate reduction and OHR may confer an advantage to marine Desulfoluna strains.
\end{abstract}

Supplementary information The online version of this article (https:// doi.org/10.1038/s41396-019-0573-y) contains supplementary material, which is available to authorized users.

Siavash Atashgahi

siavash.atashgahi@wur.nl

1 Laboratory of Microbiology, Wageningen University \& Research, Stippeneng 4, 6708 WE Wageningen, The Netherlands

2 Department of Applied and Ecological Microbiology, Institute of Microbiology, Friedrich Schiller University, 07743 Jena, Germany

3 College of Environmental Science and Engineering, Hunan University, 410082 Changsha, China

4 Laboratory of Systems and Synthetic Biology, Wageningen University \& Research, Stippeneng 4, 6708 WE Wageningen, The Netherlands

5 Department of Biology, University of Konstanz, 78457 Konstanz, Germany

6 The Konstanz Research School Chemical Biology, University of Konstanz, 78457 Konstanz, Germany

\section{Introduction}

More than 5000 naturally produced organohalides have been identified, some of which have already been present in a variety of environments for millions of years [1]. In

7 Department of Biochemistry and Microbiology, Rutgers University, New Brunswick, NJ 08901, USA

8 Department of Marine Microbiology and Biogeochemistry, NIOZ Royal Netherlands Institute for Sea Research, P.O. Box 59, 1790 AB Den Burg, The Netherlands

9 Department of Earth Sciences, Faculty of Geosciences, Utrecht University, P.O. Box 80.121, 3508 TA Utrecht, The Netherlands

10 Centre of Biological Engineering, University of Minho, Campus de Gualtar, 4710-057 Braga, Portugal

11 Present address: Department of Molecular Toxicology, Research Group Intestinal Microbiology, German Institute of Human Nutrition (DIfE), Potsdam-Rehbrücke, Arthur-Scheunert-Allee 114-116, 14458 Nuthetal, Germany 
particular, marine environments are a rich source of chlorinated, brominated and iodinated organohalides produced by marine algae, seaweeds, sponges, and bacteria [2], Fenton-like [3] and photochemical reactions, as well as volcanic activities $[4,5]$. Such a natural and ancient presence of organohalogens in marine environments may have primed development of various types of microbial dehalogenation [6]. Furthermore, marine environments and coastal regions in particular are also commonly reported to be contaminated with organohalogens from anthropogenic sources [7].

During organohalide respiration (OHR) organohalogens are used as terminal electron acceptors, and their reductive dehalogenation is coupled to energy conservation [8-10]. This process is mediated by reductive dehalogenases (RDases), which are membrane-associated, corrinoiddependent, and oxygen-sensitive proteins [9-11]. The corresponding $r d h$ gene clusters usually consist of $r d h A$ encoding the catalytic subunit, $r d h B$ encoding a putative membrane anchor protein [10], and a variable set of accessory genes encoding $\mathrm{RdhC}$ and other proteins likely involved in regulation, maturation and/or electron transport $[12,13]$. The electron transport chain from electron donors to RDases has been classified into quinone-dependent (relying on menaquinones as electron shuttles between electron donors and RDases) and quinone-independent pathways [9, 10, 14]. Recent studies suggested that RdhC may serve as electron carrier during OHR in Firmicutes $[15,16]$.

OHR is mediated by organohalide-respiring bacteria (OHRB), which belong to a broad range of phylogenetically distinct bacterial genera. OHRB belonging to Chloroflexi or the genus Dehalobacter (Firmicutes, e.g., Dehalobacter restrictus) are specialists restricted to OHR, whereas proteobacterial OHRB and members of the genus Desulfitobacterium (Firmicutes, e.g., Desulfitobacterium hafniense) are generalists with a versatile metabolism [17, 18]. Numerous studies have reported OHR activity and occurrence of OHRB and $r d h A$ genes in marine environments [6, 19-21]. Recent genomic [22-24] and single-cell genomic [25] analyses revealed widespread occurrence of $r d h$ gene clusters in marine Deltaproteobacteria, indicting untapped potential for OHR. Accordingly, OHR metabolism was experimentally verified in three Deltaproteobacteria strains, not previously known as OHRB [23].

OHRB, and in particular members of the Chloroflexi, are fastidious microbes, and lack the ability to synthesize corrinoid co-factors de novo [9]. Moreover, many OHRB are susceptible to inhibition by oxygen [26], sulfate [27] or sulfide [28, 29]. For example, in the presence of both 3chlorobenzoate and either sulfate, sulfite or thiosulfate, Desulfomonile tiedjei isolated from sewage sludge preferentially performed sulfur oxyanion reduction [30], and
OHR inhibition was suggested to be caused by downregulation of $r d h$ gene expression [30]. In contrast, concurrent sulfate reduction and OHR was observed in Desulfoluna spongiiphila $\mathrm{AA}^{\mathrm{T}}$ isolated from the marine sponge Aplysina aerophoba [20], and three newly characterized organohalide-respiring marine deltaproteobacterial strains [23]. Thus, sulfate- and sulfide-rich marine environments may have exerted a selective pressure resulting in development of sulfate- and sulfide-tolerant OHRB.

The genus Desulfoluna comprises two anaerobic sulfatereducing strains, D. spongiiphila $\mathrm{AA}^{\mathrm{T}}$ isolated from the bromophenol-producing marine sponge Aplysina aerophoba [20, 31], and D. butyratoxydans $\mathrm{MSL71}^{\mathrm{T}}$ isolated from estuarine sediments [32]. Strain $\mathrm{AA} 1^{\mathrm{T}}$ can reductively dehalogenate various bromophenols but not chlorophenols. The genome of strain $\mathrm{AA} 1^{\mathrm{T}}$ harbors three $r d h A$ genes, one of which was shown to be induced by 2,6-dibromophenol (2,6-DBP) [21]. The OHR potential and the genome of strain MSL7 ${ }^{\mathrm{T}}$ have not been studied before. In this study, a third member of the genus Desulfoluna, designated D. spongiiphila strain $\mathrm{DBB}$, was isolated from a marine intertidal sediment. The OHR metabolism of strains DBB and $\mathrm{MSL}_{71}{ }^{\mathrm{T}}$ was verified in this study, providing further evidence for widespread OHR potential in marine Deltaproteobacteria [22-25]. Using in depth physiological, genomic and proteomic analyses, we aimed to unravel metabolic traits of these three strains, such as de novo corrinoid biosynthesis, resistance to sulfate, sulfide and oxygen, and versatility in using electron donors. Our results showed that resistance of Desulfoluna strains to sulfide was remarkable among the reported sulfate-reducing bacteria, and concurrent reduction of sulfate and organohalogens as terminal electron acceptors was unique among the currently known OHRB. Moreover, inability to dehalogenate organochlorines indicated niche specialization of the members of the genus Desulfoluna as chemoorganotrophic facultative OHRB in marine environments rich in sulfate and organobromines.

\section{Materials and methods}

\section{Chemicals}

Brominated, iodinated and chlorinated benzenes and phenols were purchased from Sigma-Aldrich. Other organic and inorganic chemicals used in this study were of analytical grade.

\section{Bacterial strains}

D. spongiiphila $\mathrm{AA} 1^{\mathrm{T}}$ (DSM $\left.17682^{\mathrm{T}}\right)$ and D. butyratoxydans MSL71 $^{\mathrm{T}}\left(\mathrm{DSM} 19427^{\mathrm{T}}\right)$ were obtained from the 
German Collection of Microorganisms and Cell Cultures (DSMZ, Braunschweig, Germany), and were cultivated as described previously [20, 32].

\section{Enrichment, isolation and cultivation of strain DBB}

Surface sediment of an intertidal zone, predominantly composed of shore sediment, was collected at the shore in L'Escala, Spain (42 $\left.7^{\prime} 35.27^{\prime \prime N}, 3^{\circ} 8^{\prime} 6.99^{\prime \prime E}\right)$. Five grams of sediment was transferred into 120 -ml bottles containing $50 \mathrm{ml}$ of anoxic medium [33] with lactate and 1,4-dibromobenzene (1,4-DBB) as the electron donor and acceptor, respectively. Vitamin (without vitamin $\mathrm{B}_{12}$ ) and trace element solution was prepared as described previously [34]. The medium contained $10-30 \mathrm{~g} / \mathrm{L} \mathrm{NaCl}$. Resazurin $(0.005 \mathrm{~g} / \mathrm{L})$ and $\mathrm{Na}_{2} \mathrm{~S} \cdot 9 \mathrm{H}_{2} \mathrm{O}(0.48 \mathrm{~g} / \mathrm{L})$ were added as redox indicator and reducing reagent, respectively. Sediment-free cultures were obtained by transferring the suspensions of the enrichment culture to fresh medium. A pure culture of a 1,4-DBB debrominating strain, designated as D. spongiiphila strain $\mathrm{DBB}$, was obtained from a dilution series on solid medium with $0.8 \%$ low gelling agarose (congealing temperature $26-30{ }^{\circ} \mathrm{C}$, Sigma-Aldrich, product number: A9414). A detailed description of enrichment, isolation and physiological characterization of strain DBB is provided in the Supplementary Information.

\section{DNA extraction and bacterial community analysis}

DNA of the intertidal sediment $(5 \mathrm{~g})$ and the 1,4-DBBrespiring enrichment culture $(10 \mathrm{ml})$ was extracted using the DNeasy PowerSoil Kit (MO-BIO, CA, USA). A 2-step PCR strategy was applied to generate barcoded amplicons from the $\mathrm{V} 1-\mathrm{V} 2$ region of bacterial $16 \mathrm{~S}$ rRNA genes as described previously [35]. Primers for PCR amplification of the 16S rRNA genes are listed in Table S1. Sequence analysis was performed using NG-Tax [36]. Operational taxonomic units (OTUs) were assigned taxonomy using uclust [37] in an open reference approach against the SILVA 16S rRNA gene reference database (LTPs128_SSU) [38]. Finally, a biological observation matrix (biom) file was generated and sequence data were further analyzed using Quantitative Insights Into Microbial Ecology (QIIME) v1.2 [39].

\section{Genome sequencing and annotation}

Genomic DNA of strains DBB and MSL71 ${ }^{\mathrm{T}}$ cells was extracted using the MasterPure ${ }^{\mathrm{TM}}$ Gram Positive DNA Purification Kit (Epicentre, WI, USA). The genomes were sequenced using the Illumina HiSeq2000 paired-end sequencing platform (GATC Biotech, Konstanz, Germany; now part of Eurofins Genomics Germany $\mathrm{GmbH}$ ). The genome of strain DBB was further sequenced by PacBio sequencing (PacBio RS) to obtain longer read lengths. Optimal assembly kmer size for strain DBB was detected using kmergenie (v.1.7039) [40]. A de novo assembly with Illumina HiSeq2000 paired-reads was made with assembler Ray (v2.3.1) [40] using a kmer size of 81. A hybrid assembly for strain DBB with both the PacBio and the Illumina HiSeq reads was performed with SPAdes (v3.7.1, kmer size: 81) [41]. The two assemblies were merged using the tool QuickMerge (v1) [42]. Duplicated scaffolds were identified with BLASTN [43] and removed from the assembly. Assembly polishing was performed with Pilon (v1.21) [44] using the Illumina HiSeq reads. Optimal assembly kmer size for strain MSL $71^{\mathrm{T}}$ was also identified using kmergenie (v.1.7039), and a de novo assembly with Illumina HiSeq2000 paired-end reads was performed with SPAdes (v3.11.1) with a kmer-size setting of 79,101,117. FastQC and Trimmomatic (v0.36) [45] was used for read inspection and trimming using the trimmomatic parameters: TRAILING:20 LEADING:20 SLIDINGWINDOW:4:20 MINLEN:50. Trimmed reads were mapped with Bowtie2 v2.3.3.1 [46]. Samtools (v1.3.1) [47] was used for converting the bowtie output to a sorted and indexed bam file. The assembly was polished with Pilon (v1.21).

\section{Transcriptional analysis of the $r d h A$ genes of $D$. spongiiphila DBB}

Transcriptional analysis was performed using DBB cells grown with lactate $(20 \mathrm{mM})$, sulfate $(10 \mathrm{mM})$ and either 1,4-DBB ( $1 \mathrm{mM})$ or 2,6-DBP $(0.2 \mathrm{mM})$. DBB cells grown with lactate and sulfate but without any organohalogens were used as control. Ten replicate microcosms were prepared for each experimental condition, and at each sampling time point, two microcosms were randomly selected and sacrificed for RNA isolation as described previously [48]. RNA was purified using RNeasy columns (Qiagen, Venlo, The Netherlands) followed by DNase I (Roche, Almere, The Netherlands) treatment. cDNA was synthesized from 200 ng total RNA using SuperScript ${ }^{\mathrm{TM}}$ III Reverse Transcriptase (Invitrogen, CA, USA) following manufacturer's instructions. Primers for RT-qPCR assays were listed in Table S1. RT-qPCR assays were performed as outlined in Supplementary Information.

\section{Protein extraction and proteomic analysis}

Triplicate $100 \mathrm{ml}$ cultures of strain DBB grown with lactate $(20 \mathrm{mM})$ and sulfate $(10 \mathrm{mM})$ (LS condition) or with lactate $(20 \mathrm{mM})$, sulfate $(10 \mathrm{mM})$, and 1,4-DBB $(100 \mu \mathrm{M})$ (LSD condition) were used for proteomic analysis. Cells were collected by centrifugation at $4500 \times g$ for $20 \mathrm{~min}$ at $4{ }^{\circ} \mathrm{C}$. The cells were then re-suspended in $1 \mathrm{ml} 100 \mathrm{mM}$ Tris- $\mathrm{HCl}$ 
buffer ( $\mathrm{pH}$ 7.5) containing $10 \mu \mathrm{l}$ protease inhibitor (Halt Protease Inhibitor Cocktail; Thermo Fisher Scientific, Rockford, USA). Cells were lysed by sonication using a Branson sonifier (Branson, CT, USA) equipped with a 3 $\mathrm{mm}$ tip by six pulses of $30 \mathrm{~s}$ with $30 \mathrm{~s}$ rest in between of each pulse. Cell debris was removed by centrifugation at $10,000 \times g$ for $10 \mathrm{~min}$ at $4{ }^{\circ} \mathrm{C}$. The protein concentration of the cell-free extracts (CFE) was determined using the Bradford assay [49]. The total-proteomics samples were purified by SDS-PAGE (see below) and the analyses were done as described by Burrichter et al. [50]. For total protein analysis, CFE corresponding to $200 \mu \mathrm{g}$ of protein was mixed with SDS-PAGE loading dye (Roti-Load 1, Carl Roth, Karlsruhe, Germany) and loaded onto an SDS gel (4\% acrylamide in the stacking and $12 \%$ in the resolving gel) until the proteins had just entered the resolving gel (without any separation); the Coomassie-stained totalprotein bands were excised and then subjected to peptide fingerprinting-mass spectrometry (see below). For analysis of proteins associated to the membrane, the membrane fragments in the CFE were separated by ultracentrifugation at $104,000 \times g$ for $35 \mathrm{~min}$ at $4{ }^{\circ} \mathrm{C}$; the membrane pellet was solubilized in SDS-PAGE loading dye (Roti-Load 1, Carl Roth, Karlsruhe, Germany) and purified by SDS-PAGE as described above. The unresolved protein bands excised from SDS-PAGE gels were subjected to peptide fingerprinting-mass spectrometry with Dr. Andreas Marquardt at the Proteomics Centre of the University of Konstanz (https://www.biologie.uni-konstanz. de/proteomics-centre/) [50]. The samples were processed by in-gel reduction with dithiothreitol, alkylation with chloroacetamide and tryptic digest. Each sample was analyzed twice on a Orbitrap Fusion with EASY-nLC 1200 (Thermo Fisher Scientific) and tandem mass spectra were searched against an appropriate protein database (see below) of strain DBB using Mascot (Matrix Science, London, UK) and Proteome Discoverer V1.3 (Thermo Fisher Scientific) with "Trypsin" enzyme cleavage, static cysteine alkylation by chloroacetamide, and variable methionine oxidation [50]. The protein database was constructed from the annotated genome of strain DBB by in vitro translation of genes. Statistical analysis was performed using prostar proteomics [51]. Top three peptide area values were $\log 2$-transformed and normalized against all columns (column sums function from prostar proteomics). The values of proteins detected in at least two of the three replicates were differentially compared and tested for statistical significance. Missing values were imputed using the SLSA function of prostar, and hypothesis testing with a student's $t$ test was performed for LSD vs LS growth conditions. The $p$ values were Benjamini-Hochberg corrected and proteins with $p$ values below 0.05 and a $\log 2$ value of 1 or larger were considered statistically significantly up- or downregulated.

\section{Analytical methods}

Halogenated benzenes and benzene were analyzed on a GC equipped with an Rxi-5Sil capillary column (Retek, PA, USA) and a flame ionization detector (GC-FID, Shimadzu 2010). Halogenated phenols and phenol were analyzed on a Thermo Scientific Accela HPLC System equipped with an Agilent Poroshell 120 EC-C18 column and a UV/Vis detector. Organic acids and sugars were analyzed using a ThermoFisher Scientific SpectraSYSTEM ${ }^{\mathrm{TM}}$ HPLC equipped with an Agilent Metacarb $67 \mathrm{H}$ column and RI/UV detectors. Sulfate, sulfite and thiosulfate were analyzed using a ThermoFisher Scientific Dionex ${ }^{\mathrm{TM}}$ ICS-2100 Ion Chromatography System equipped with a Dionex ${ }^{\mathrm{TM}}$ Ion$\mathrm{pac}^{\mathrm{TM}}$ AS17 IC column and a suppressed conductivity detector. Cell growth under sulfate-reducing conditions was determined by measuring $\mathrm{OD}_{600}$ using a WPA CO8000 cell density meter (Biochrom, Cambridge, UK). Cell growth of strain DBB during OHR and in absence of sulfate was determined by quantifying the $16 \mathrm{~S}$ rRNA gene copy number using qPCR. Sulfide was measured by a photometric method using methylene blue as described previously [52].

\section{Strain and data availability}

D. spongiiphila strain DBB was deposited at DSMZ under accession number DSM 104433. The 16S rRNA gene sequences of strain DBB were deposited in GenBank (accession numbers: MK881098-MK881099). The genome sequences of strains DBB and MSL71 were deposited in the European Bioinformatics Institute (accession number: GCA_902498735 (DBB), GCA_900699765 (MSL71 $\left.{ }^{\mathrm{T}}\right)$ ). A list of proteins detected from strain DBB under LS and LSD growth conditions is available in Dataset $\mathrm{S} 1$.

\section{Results and discussion}

\section{Enrichment of 1,4-DBB debrominating cultures and isolation of strain DBB}

Reductive debromination of 1,4-DBB to bromobenzene (BB) and benzene was observed in the original cultures containing intertidal sediment (Fig. 1a, b). Debromination of 1,4-DBB was maintained in the subsequent sediment-free transfer cultures (Fig. 1c). However, benzene was no longer detected and $\mathrm{BB}$ was the only debromination product, indicating loss of the BB-debrominating population. Up to date, the only known OHRB that can debrominate BB to benzene is Dehalococcoides mccartyi strain CBDB1 [53]. 1,4-DBB debromination to BB was stably maintained during subsequent transfers (data not shown) and after serial dilution (Fig. 1d). Bacterial community analysis showed an 


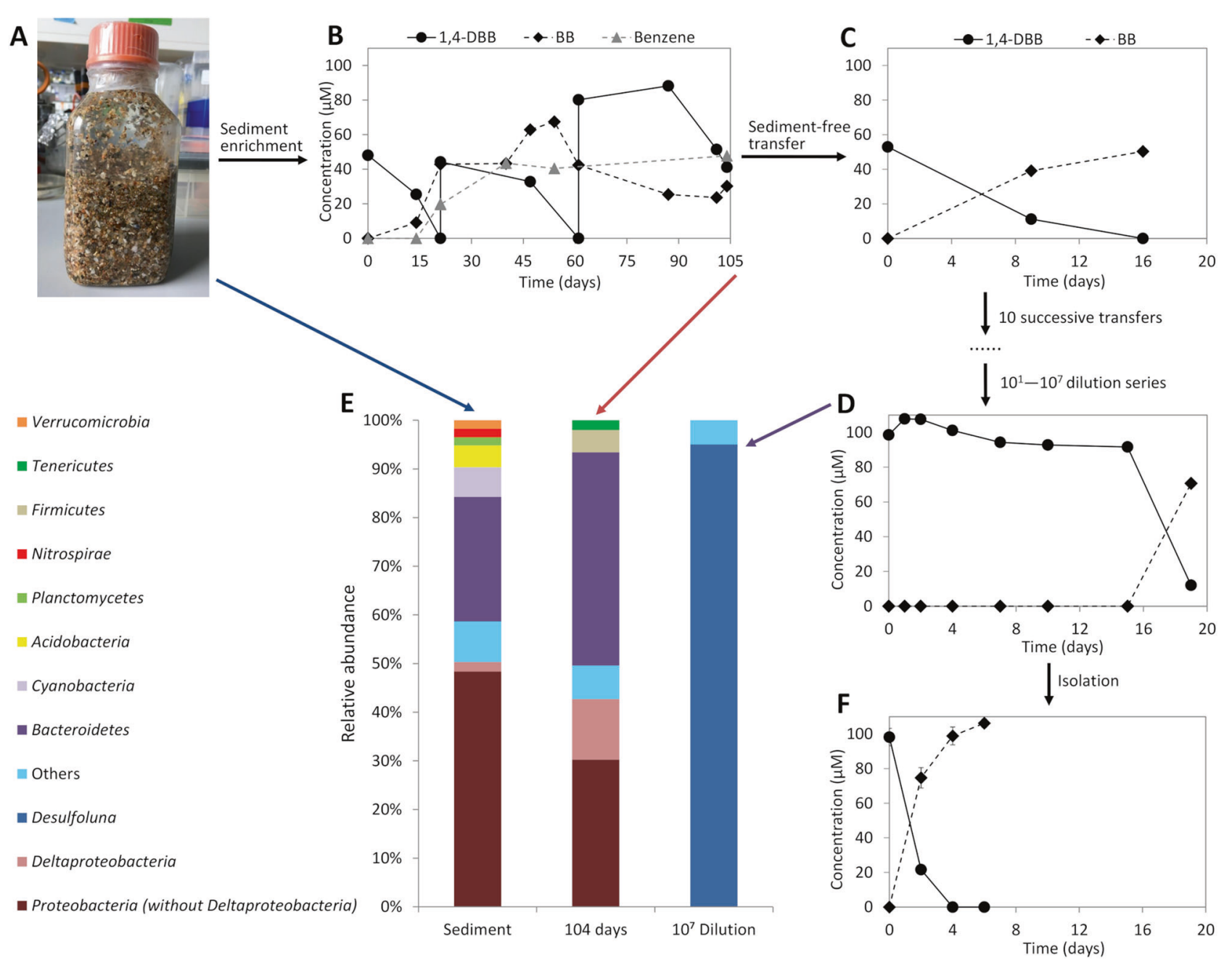

Fig. 1 Enrichment and isolation of $D$. spongïphila DBB. Intertidal sediment mainly composed of shore sediment used for isolation (a). Reductive debromination of 1,4-dibromobenzene (1,4-DBB) by: the original microcosms containing intertidal sediment (b), the sedimentfree enrichment cultures (c), the most diluted culture $\left(10^{7}\right)$ in the dilution series (d). Phylogenetic analysis of bacterial communities in the microcosms from the shore sediment at time zero (left), the original 1,4-DBB debrominating enrichment culture after 104 days incubation (middle) and the $10^{7}$ dilution series culture (right) (e). Reductive

increase in the relative abundance of Deltaproteobacteria from $\sim 2 \%$ in the intertidal sediment at time zero to $\sim 13 \%$ after 104 days of enrichment (Fig. 1e). The genus Desulfoluna was highly enriched from below $0.1 \%$ relative abundance in the original sediment to more than $80 \%$ relative abundance in the most diluted culture $\left(10^{7}\right.$ dilution) (Fig. 1e).

Single colonies were observed in roll tubes with $0.8 \%$ low-melting agarose after 15 days of incubation. Among the six single colonies randomly selected and transferred to liquid media, one showed 1,4-DBB debromination (Fig. 1f) which was again subjected to the roll tube isolation procedure to ensure purity. The final isolated strain was designated strain DBB. debromination of 1,4-DBB to bromobenzene (BB) by the isolated pure culture (f). Sediment enrichment culture and sediment-free transfer cultures (b-d) were prepared in single bottles. Pure cultures (f) were prepared in duplicate bottles. Points and error bars represent the average and standard deviation of samples taken from the duplicate cultures. Phylogenetic data are shown at phylum level, except Deltaproteobacteria shown at class level and Desulfoluna at genus level. Taxa comprising less than $1 \%$ of the total bacterial community are categorized as 'Others'.

\section{Characterization of the Desulfoluna strains}

Cells of strain DBB were slightly curved rods with a length of $1.5-3 \mu \mathrm{m}$ and a diameter of $0.5 \mu \mathrm{m}$ as revealed by SEM (Figs. S1A and S1B), which was similar to strain $\mathrm{AA} 1^{\mathrm{T}}$ (Fig. S1C) and $\mathrm{MSL}^{\mathrm{T}}{ }^{\mathrm{T}}$ (Fig. S1D). In contrast to strain $\mathrm{AA}^{\mathrm{T}}{ }^{\mathrm{T}}$ [20], but similar to strain MSL71 ${ }^{\mathrm{T}}$ [32], strain DBB was motile when observed by light microscopy, with evident flagella being observed by SEM (Fig. S1A, B).

The cellular fatty acid profiles of the three strains consisted mainly of even-numbered saturated and monounsaturated fatty acids (Table S2).

Strain DBB used lactate, pyruvate, formate, malate and butyrate as electron donors for sulfate reduction (Table 1). 
Lactate was degraded to acetate, which accumulated without further degradation, and sulfate was reduced to sulfide (Fig. S2A). In addition, sulfite and thiosulfate were utilized as electron acceptors with lactate as the electron donor (Table 1). Sulfate and 1,4-DBB could be concurrently utilized as electron acceptors by strain DBB (Fig. S2). Independent of the presence of sulfate in the medium, strain DBB stoichiometrically debrominated 1,4-DBB to bromobenzene (BB), and 2bromophenol (2-BP), 4-bromophenol (4-BP), 2,4-bromophenol (2,4-DBP), 2,6-DBP, 2,4,6-tribromophenol (2,4,6-TBP), 2-iodophenol (2-IP) and 4-iodophenol (4-IP) to phenol (Table 1) using lactate as the electron donor. In the absence of sulfate, the growth yield of strain DBB was $(8.6 \pm 4.4) \times 10^{12}$ 16S rRNA gene copies per mol bromide released from 1,4-DBB indicating energy conservation by reductive debromination. Hydrogen was not used as an electron donor for 1,4-DBB debromination or sulfate reduction (data not shown). Strain DBB was unable to dehalogenate the tested chlorinated aromatic compounds and several other bromobenzenes listed in Table 1 . This is in accordance with the dehalogenating activity reported for strain $\mathrm{AA}^{\mathrm{T}}$ that was unable to use chlorinated aromatic compounds as electron acceptors [20]. The majority of the known organohalogens from marine environments are brominated [1] and hence marine OHRB may be less exposed to organochlorine compounds in their natural habitats. For instance, strain $\mathrm{AA}^{\mathrm{T}}$ was isolated from the marine sponge Aplysina aerophoba [20] in which organobromine metabolites can account for over $10 \%$ of the sponge dry weight [54].

\section{Genomic and phylogenetic characterization of the Desulfoluna strains}

The three Desulfoluna strains showed similar overall genome features (Table 1, Tables S3 and S4). The complete genome of strain DBB consists of a single chromosome with a size of $6.68 \mathrm{Mbp}$ (Fig. S3). The genomes of strain AA1 ${ }^{\mathrm{T}}$ (GenBank accession number: NZ_FMUX01000001.1) and strain MSL71 ${ }^{\mathrm{T}}$ (sequenced in this study) are draft genomes with similar $\mathrm{G}+\mathrm{C}$ content (Table 1). The average nucleotide identity (ANI) of the DBB genome to $\mathrm{AA}^{\mathrm{T}}$ and

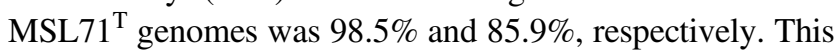
indicates that $\mathrm{DBB}$ and $\mathrm{AA} 1^{\mathrm{T}}$ strains belong to the same species of D. spongiiphila [55]. 16S rRNA gene and protein domain-based phylogenetic analyses with other genera of the Desulfobacteraceae placed Desulfoluna strains in a separate branch of the corresponding phylogenetic trees (Fig. S4). Whole-genome alignment of strains DBB, AA $1^{\mathrm{T}}$ and MSL71 ${ }^{\mathrm{T}}$ revealed the presence of 11 locally colinear blocks (LCBs) with several small regions of inversion and rearrangement (Fig. S5). A site-specific recombinase gene (DBB_14420) was found in one of the LCBs. The same
Table 1 Physiological and genomic properties of Desulfoluna strains.

\begin{tabular}{|c|c|c|c|}
\hline Strain & DBB & $\mathrm{AA} 1^{\mathrm{Ta}}$ & $\operatorname{MSL}_{71^{\mathrm{T} b}}$ \\
\hline Isolation source & $\begin{array}{l}\text { Marine intertidal } \\
\text { sediment }\end{array}$ & Marine sponge & $\begin{array}{l}\text { Estuarine } \\
\text { sediment }\end{array}$ \\
\hline Cell morphology & Curved rods & Curved rods & Curved rods \\
\hline $\begin{array}{l}\text { Optimum } \mathrm{NaCl} \\
\text { concentration (\%) }\end{array}$ & 2.0 & 2.5 & 2.0 \\
\hline $\begin{array}{l}\text { Temperature optimum/ } \\
\text { range }\left({ }^{\circ} \mathrm{C}\right)\end{array}$ & $30 / 10-30$ & $28 / 10-36$ & $30 / \mathrm{ND}^{\mathrm{c}}$ \\
\hline \multicolumn{4}{|l|}{$\begin{array}{l}\text { Utilization of } \\
\text { electron donors }\end{array}$} \\
\hline Lactate & + & + & + \\
\hline Butyrate & + & - & + \\
\hline Formate & + & + & + \\
\hline Acetate & - & - & - \\
\hline Fumarate & - & - & - \\
\hline Citrate & - & + & - \\
\hline Glucose & - & + & - \\
\hline Malate & + & + & + \\
\hline Pyruvate & + & + & + \\
\hline Hydrogen & $-^{\mathrm{d}}$ & ND & + \\
\hline Propionate & - & - & - \\
\hline Succinate & - & - & - \\
\hline \multicolumn{4}{|l|}{$\begin{array}{l}\text { Utilization of electron } \\
\text { acceptors }\end{array}$} \\
\hline Sulfate & + & + & + \\
\hline Sulfite & + & + & + \\
\hline Thiosulfate & + & + & + \\
\hline 1,4-Dibromobenzene & + & $+^{\mathrm{e}}$ & $-^{\mathrm{e}}$ \\
\hline 1,2-Dibromobenzene & - & ND & ND \\
\hline 1,3-Dibromobenzene & - & ND & ND \\
\hline 1,2,4-Tribromobenzene & - & ND & ND \\
\hline Bromobenzene & - & ND & ND \\
\hline 1,2-Dichlorobenzene & - & ND & ND \\
\hline 1,3-Dichlorobenzene & - & ND & ND \\
\hline 1,4-Dichlorobenzene & - & ND & ND \\
\hline 1,2,4-Trichlorobenzene & - & ND & ND \\
\hline 2-Bromophenol & + & + & $+^{\mathrm{e}}$ \\
\hline 4-Bromophenol & + & + & $-^{\mathrm{e}}$ \\
\hline 2,4-Dibromophenol & + & + & $+^{\mathrm{e}, \mathrm{f}}$ \\
\hline 2,6-Dibromophenol & + & + & $+^{\mathrm{e}}$ \\
\hline 2,4,6-Tribromophenol & + & + & $+^{\mathrm{e}, \mathrm{f}}$ \\
\hline 2-Iodophenol & + & $+^{\mathrm{e}}$ & $-^{\mathrm{e}}$ \\
\hline 4-Iodophenol & + & $+^{\mathrm{e}}$ & $-^{\mathrm{e}}$ \\
\hline 2,4-Dichlorophenol & - & - & $-^{\mathrm{e}}$ \\
\hline 2,6-Dichlorophenol & - & - & $-^{\mathrm{e}}$ \\
\hline 2,4,6-Trichlorophenol & - & - & $-^{\mathrm{e}}$ \\
\hline \multicolumn{4}{|l|}{ Genomic information } \\
\hline Genome size $(\mathrm{Mb})$ & 6.68 & $6.53^{\mathrm{g}}$ & $6.05^{\mathrm{h}}$ \\
\hline $\mathrm{G}+\mathrm{C}$ content $(\%)$ & 57.1 & $57.9^{g}$ & $57.2^{\mathrm{h}}$ \\
\hline Total genes & 5497 & $5356^{\mathrm{g}}$ & $4894^{\mathrm{h}}$ \\
\hline Total proteins & 5301 & $5203^{\mathrm{g}}$ & $4186^{\mathrm{h}}$ \\
\hline
\end{tabular}

${ }^{\mathrm{a} D a t a}$ from Ahn et al. [20]

${ }^{\mathrm{b}}$ Data from Suzuki et al. [32]

${ }^{\mathrm{c}} \mathrm{ND}$ not determined

${ }^{\mathrm{d}}$ Tested with 1,4-dibromobenzene as the electron acceptor

${ }^{\mathrm{e}}$ Data from this study

f 4-Bromophenol rather than phenol was the debromination product

${ }^{\mathrm{g}}$ Data from GenBank (accession number: NZ_FMUX01000001.1)

${ }^{\text {h}}$ Predicted based on draft genome 


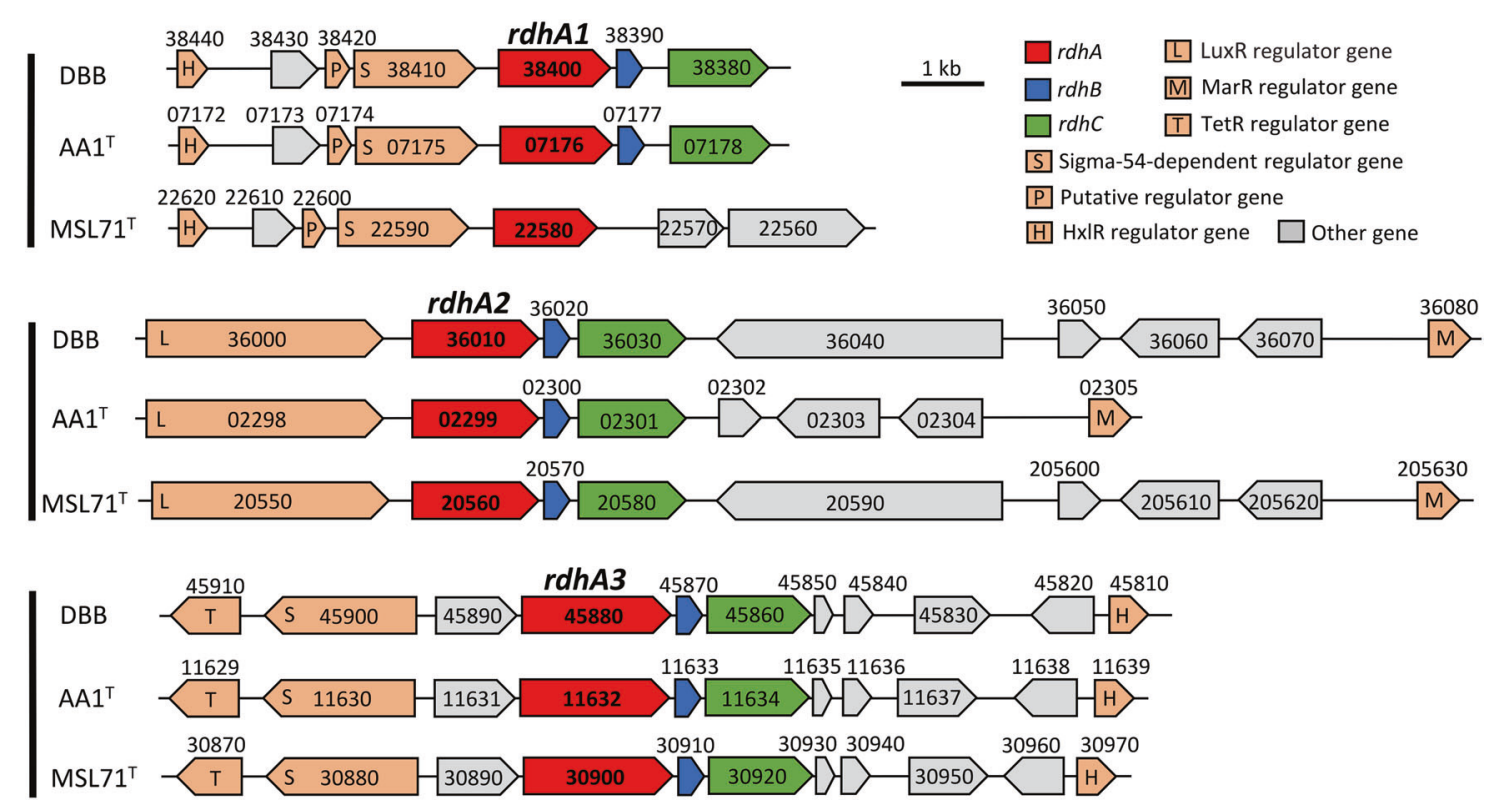

Fig. 2 Comparison of the $r d h$ gene clusters in D. spongiiphila DBB, D. spongiiphila $\mathrm{AA1}^{\mathrm{T}}$ and D. butyratoxydans MSL71 ${ }^{\mathrm{T}}$. Numbers indicate the locus tags of the respective genes.

gene was also found in the corresponding inversed and rearranged LCBs in $\mathrm{AA}^{\mathrm{T}}{ }^{\text {(AA1_11599) and MSL71 }}{ }^{\mathrm{T}}$ (MSL71_48620), suggesting a role of the encoded recombinase in genomic rearrangement in the Desulfoluna strains.

\section{Comparison of the $r d h$ gene region of the Desulfoluna strains}

Similar to strain $\mathrm{AA}^{\mathrm{T}}$ [21], the genomes of strains DBB and MSL71 ${ }^{\mathrm{T}}$ also harbor three $r d h A$ genes. The amino acid sequences of the RdhA homologs in DBB share $>99 \%$ identity to the corresponding RdhAs in $\mathrm{AAl}^{\mathrm{T}}$, and $80-97 \%$ identity with the corresponding RdhAs in MSL71 ${ }^{\mathrm{T}}$ (Fig. 2). However, the three distinct RdhA homologs in the Desulfoluna strains share low identity (20-30\%) with each other, and they form three distant branches in the phylogenetic tree of RdhAs [18], and cannot be grouped with any of the currently known RdhA groups (Fig. S6). Therefore, we propose three new RdhA homolog groups, RdhA1 including DBB_38400, AA1_07176 and MSL71_22580; RdhA2 including DBB_36010, AA1_02299 and MSL71_20560, and RdhA3 including DBB_45880, AA1_11632 and MSL71_30900 (Fig. 2, Fig. S6).

The $r d h$ gene clusters in DBB and MSL71 ${ }^{\mathrm{T}}$ show a similar gene order as the corresponding $r d h$ gene clusters in $\mathrm{AA}^{\mathrm{T}}$ (Fig. 2), except that the $r d h A l$ gene cluster of MSL71 ${ }^{\mathrm{T}}$ lacks $r d h B$ and $r d h C$. Genes encoding sigma-54-dependent transcriptional regulators in the $r d h A l$ and $r d h A 3$ gene clusters of $\mathrm{AA}^{\mathrm{T}}{ }^{\text {[21] }}$ are also present in the corresponding gene clusters of DBB and MSL71 ${ }^{\mathrm{T}}$ (Fig. 2). Likewise, genes encoding the LuxR and MarR-type regulators are present up- and downstream of the $r d h A 2$ gene clusters of DBB and MSL71 ${ }^{\mathrm{T}}$, in line with the organization of the $r d h A 2$ gene cluster of $\mathrm{AA} 1^{\mathrm{T}}$ (Fig. 2). This may indicate similar regulation systems of the $r d h$ genes in the Desulfoluna strains studied here. The conserved motifs from known RDases (RR, C1-C5, FeS1, and FeS2) [56, 57] are also conserved among all the RdhAs of the Desulfoluna strains, except for RdhA1 of MSL71 ${ }^{\mathrm{T}}$, which lacks the RR motif (Fig. S7). This may indicate a cytoplasmic localization and a non-respiratory role of RdhA1 in strain MSL71 ${ }^{\mathrm{T}}[6]$.

\section{OHR metabolism of D. butyratoxydans MSL71 ${ }^{\top}$}

Guided by the genomic potential of strain MSL $71^{\mathrm{T}}$ for OHR, physiological experiments in this study confirmed that strain MSL71 $^{\mathrm{T}}$ is indeed capable of using 2-BP, 2,4-DBP, 2,6-DBP and 2,4,6-TBP as electron acceptors with lactate as the electron donor. Similar to $\mathrm{DBB}$ and $\mathrm{AA} 1^{\mathrm{T}}$, chlorophenols such as 2,4-DCP, 2,6-DCP and 2,4,6-TCP were not dehalogenated by strain MSL $71^{\mathrm{T}}$ (Table 1). In contrast to strains $\mathrm{DBB}$ and $\mathrm{AA} 1^{\mathrm{T}}$, strain $\mathrm{MSL}^{\mathrm{T}}{ }^{\mathrm{T}}$ was unable to debrominate 1,4-DBB and 4-BP. Hence, debromination of 2,4-DBP and 2,4,6-TBP was incomplete with 4-BP as the final product rather than phenol (Table 1). Moreover, strain MSL71 $^{\mathrm{T}}$ was unable to deiodinate 2-IP and 4-IP, again in contrast to strains DBB and $\mathrm{AA}^{\mathrm{T}}$ (Fig. S8, Table 1).

\section{Induction of $r d h A$ genes during OHR by strain DBB}

When strain DBB was grown with sulfate and 1,4-DBB with concomitant production of BB (Fig. 3a), its rdhAl 
gene showed significant up-regulation (60-fold) at $24 \mathrm{~h}$, reached its highest level (120-fold) at $48-72 \mathrm{~h}$, and then decreased (Fig. 3b). In contrast, no significant up-regulation of $r d h A 2$ or $r d h A 3$ was noted, suggesting that RdhA1 mediates 1,4-DBB debromination. Accordingly, RdhA1 was found in the proteome of the LSD growth condition but not in that of the LS condition (Table S5, Datasets S2, S3). When strain DBB was grown with sulfate and 2,6-DBP, both $r d h A 1$ and $r d h A 3$ were significantly up-regulated and reached their highest level at $4 \mathrm{~h}$ (65- and 2000-fold, respectively, Fig. 3d). However, $r d h A 3$ was the dominant gene at $8 \mathrm{~h}$ (Fig. 3d), after which 2-BP was debrominated to phenol (Fig. 3c), indicating a role of RdhA3 in 2,6-DBP and 2-BP debromination by strain DBB. A previous transcriptional study of the $r d h A$ genes in strain $\mathrm{AA}^{\mathrm{T}}$ during 2,6-DBP debromination also showed a similar induction of its $r d h A 3$ [21].

\section{Corrinoid biosynthesis in Desulfoluna strains}

Most known RDases depend on corrinoid cofactors such as cyanocobalamin for dehalogenation activity [10]. Both strains DBB (this study) and $\mathrm{AA}^{\mathrm{T}}{ }^{\text {[21] were capable of }}$ OHR in the absence of externally added cobalamin. With one exception (cbiJ), the genomes of the Desulfoluna strains studied here harbor all genes necessary for de novo anaerobic corrinoid biosynthesis starting from glutamate (Table S6). The genes for cobalamin biosynthesis from precorrin-2 are arranged in one cluster (DBB_3730-3920, AA1_12810-12829, MSL71_49290-49480) including an $\mathrm{ABC}$ transporter (btuCDF) for cobalamin import (Fig. 4). Three of the proteins encoded by DBB_3730-3920 (Cbik:
3730, CbiL: 3790, CbiH: 3850) could be quantified in the proteome of cells grown under both the LS and LSD conditions, whereas CobH/CbiC (3780) and CobU (3880) could be quantified for LSD and LS conditions, respectively (Table S5, Datasets S2, S3). The abundance of the cobalamin biosynthesis proteins was not significantly different between LS and LSD conditions (Table S5, Datasets S2, $\mathrm{S} 3$ ), except for the tetrapyrrole methylase $\mathrm{CbiH}$ encoded by DBB_3850 that was significantly more abundant in LSD cells (Table S5, Dataset S3). The detection of cobalamin biosynthesis proteins in the absence of 1,4-DBB in LS condition could be due to the synthesis of corrinoiddependent enzymes in the absence of an organohalogen. Accordingly, three corrinoid-dependent methyltransferase genes (encoded by DBB_7090, 43520, 16050) were detected in the proteomes, which might be involved in methionine, methylamine or $O$-demethylation metabolism. This might also indicate a constitutive expression of the corresponding genes, in contrast to the organohalideinduced cobalamin biosynthesis in Sulfurospirillum multivorans [58].

\section{Sulfur metabolism and impact of sulfate and sulfide on debromination by Desulfoluna strains}

All three strains were capable of using sulfate, sulfite, and thiosulfate as terminal electron acceptors (Table 1). Among the four sulfate permeases encoded in the genomes of the Desulfoluna strains (Table S7), one (DBB_22290) was detected in DBB cells grown under LS and LSD conditions (Table S5, Dataset, S3). The genes involved in sulfate reduction, including those encoding sulfate
Fig. 3 Differential induction of $r d h A$ genes during 1,4-DBB and 2,6-DBP debromination by $D$. spongiiphila $\mathrm{DBB}$. Debromination of 1,4-DBB (a) and 2,6-DBP (c) by strain DBB and RT-qPCR analysis of relative induction of its three $r d h A$ genes during debromination of $1,4-$ DBB (b) and 2,6-DBP (d). Error bars in panels $\mathbf{a}$ and $\mathbf{c}$ indicate the standard deviation of two random cultures analyzed out of 10 replicates. The concentration of 1,4-DBB (>0.1 mM) could not be accurately measured due to large amount of undissolved compound and hence was not plotted. Error bars in panels $\mathbf{b}$ and d indicate standard deviation of triplicate RT-qPCRs performed on samples withdrawn from duplicate cultures at each time point $(n=2 \times 3)$.
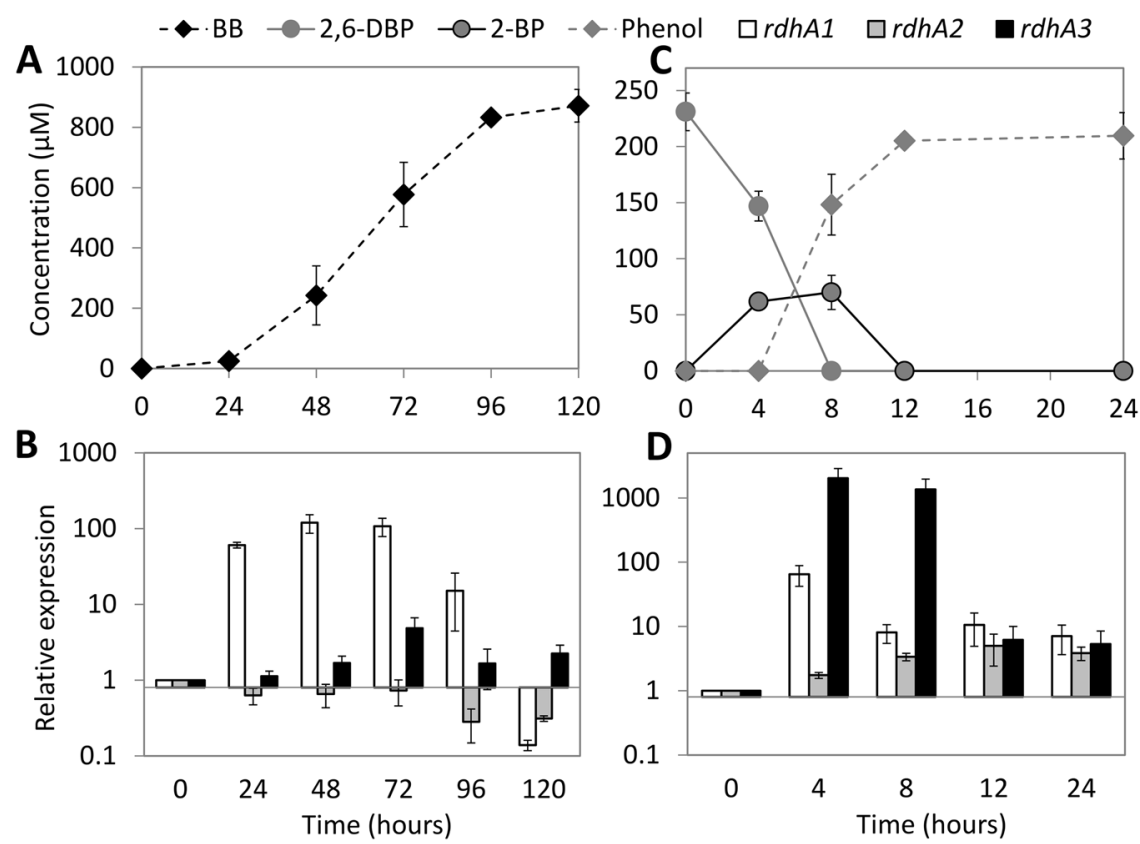


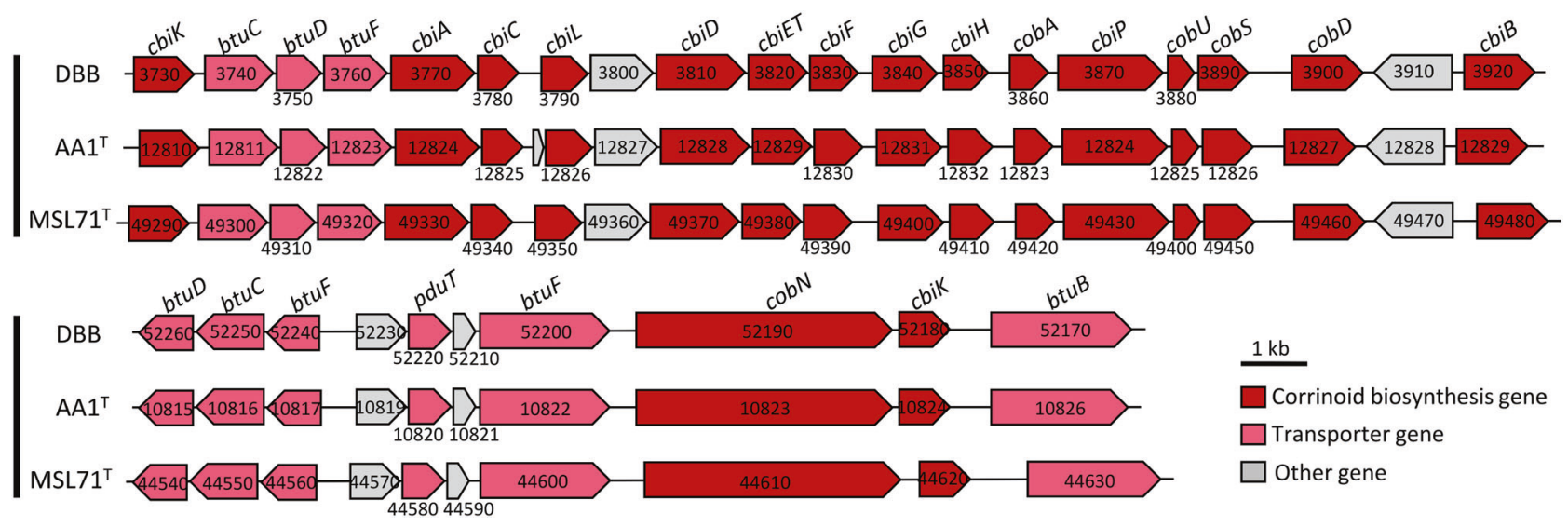

Fig. 4 Corrinoid biosynthesis and transporter gene clusters of Desulfoluna strains. Numbers indicate the locus tags of the respective genes. The corresponding enzymes encoded by the genes and their functions in corrinoid biosynthesis are indicated in Table S4.

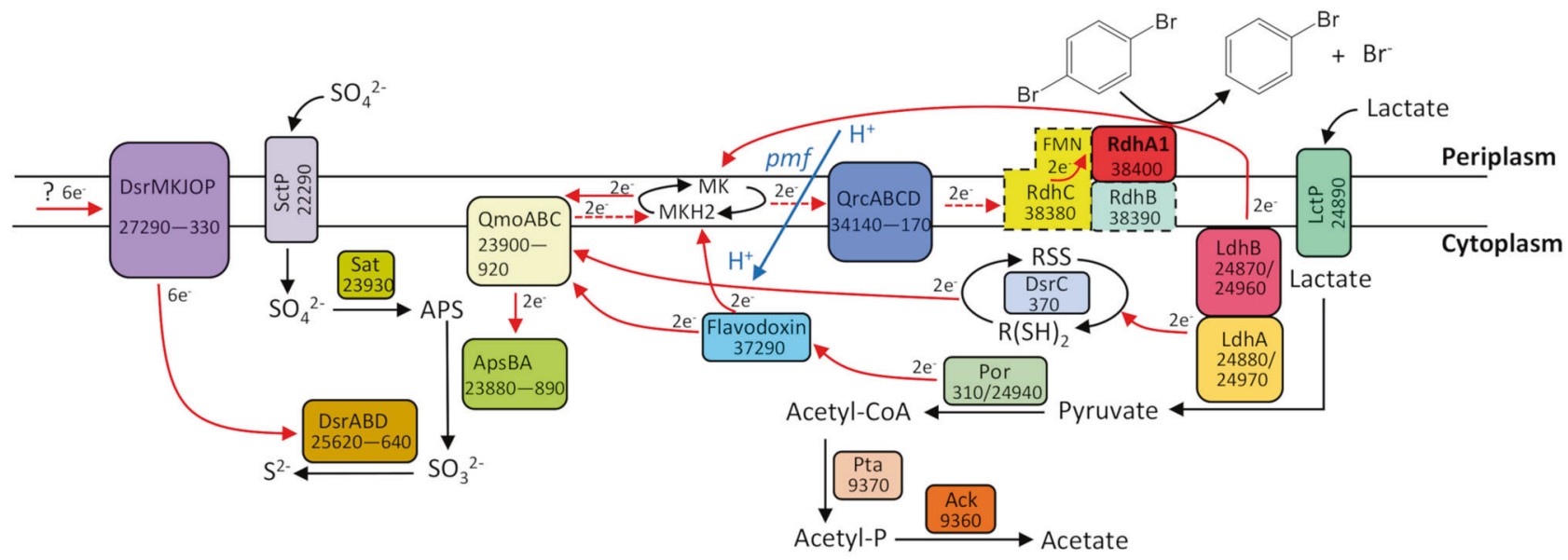

Legend:

Ack: acetate kinase ApsBA: APS reductase DsrABD: dissimilatory sulfite reductase

DsrC: dissimilatory sulfite reductase gamma subunit DsrMKJOP: electron transport complex function with DsrABD LdhA: lactate dehydrogenases

LdhB: HdrD-like putative subunits for LdhA

LctP: lactate permease

MK: menaquinone pool

Por: pyruvate oxidoreductase

Pta: phosphate acetyltransferase

Fig. 5 Preliminary electron transport pathway scheme based on the genomic and proteomic analysis of $D$. spongiiphila DBB grown on lactate, sulfate and 1,4-DBB (LSD condition). Corresponding gene locus tags are given for each protein. Proteins shown in dashed line square were not detected under the tested conditions. Probable electron flow path is shown in red arrows, and the dashed red arrows

adenylyltransferase (Sat), APS reductase (AprBA) and dissimilatory sulfite reductase (DsrAB), were identified in the genomes of all three strains (Table S7). The corresponding proteins were detected in DBB cells grown under both LS and LSD conditions (Fig. 5, Table S5) with pmf: proton motive force

QmoABC: electron transport complex QrCABCD: electron transport complex

RdhA1: reductive dehalogenase catalytic subunit RdhB: putative membrane anchor protein for RdhA1 RdhC: putative electron transport protein for RdhA1 $\mathrm{R}(\mathrm{SH})_{2}$ and RSS: reduced and oxidized forms of thiol-disulfide redox pair SctP: sulfate permease Sat: sulfate adenylyltransferase ?: unknown processes

indicate reverse electron transport. The pmf is built up by ATPase using ATP generated by substrate-level phosphorylation via Por, Pta and Ack. Note that the distribution of electrons to the electron transport chains is not equal between sulfate respiration and OHR, but shifted heavily toward sulfate respiration due to excess sulfate $(20 \mathrm{mM}$

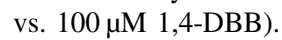

AprBA, disulfite reductase (DsrMKJOP) and Sat among the most abundant proteins in both, soluble and membrane fractions (Datasets S2, S3). Interestingly, thiosulfate reductase genes were not found in any of the three genomes, whereas all strains can use thiosulfate as the electron 
acceptor (Table 1). Desulfitobacterium metallireducens was also reported to reduce thiosulfate despite lacking a known thiosulfate reductase gene $[59,60]$, suggesting the existence of a not-yet-identified gene encoding a thiosulfate reductase [60].

Sulfate and sulfide are known inhibitors for many OHRB [30, 61, 62]. However, debromination of 2,6-DBP was not affected in Desulfoluna strains in the presence of up to 20 mM sulfate (Fig. S9B, D, F), and sulfate and 2,6-DBP were reduced concurrently (Fig. S9). This is similar to some other Deltaproteobacteria [23], but in contrast to D. tiedjei which preferentially performs sulfate reduction over OHR with concomitant downregulation of $r d h$ gene expression [30]. Moreover, sulfide, an RDase inhibitor in D. tiedjei [63] and Dehalococcoides mccartyi strains [28, 29], did not impact 2,6-DBP debromination by Desulfoluna strains even at a concentration of $10 \mathrm{mM}$ (Fig. S10A-F). However, debromination was delayed in the presence of $20 \mathrm{mM}$ sulfide, and no debromination was noted in the presence of $30 \mathrm{mM}$ sulfide (Fig. S10G-L). This high resistance to sulfide was not reported before for the known OHRB, and is also rare among sulfate-reducing bacteria [64], and may confer an ecological advantage to these sulfate-reducing OHRB.

\section{Electron transport chains of strain DBB}

Based on previous studies with Desulfovibrio vulgaris Hildenborough and Desulfovibrio alaskensis G20 that are phylogenetically related to Desulfoluna (Fig. S4), the following electron transport pathway in strain DBB with lactate and sulfate can be proposed (Fig. 5): the two Ldhs either reduce menaquinone directly, or transfer electrons via their HdrDlike subunit LdhB and DsrC (a high redox potential electron carrier with disulfide/dithiol $\left(\mathrm{RSS} / \mathrm{R}(\mathrm{SH})_{2}\right)$ ) to QmoA $[65,66]$. The pyruvate produced by lactate oxidation is further oxidized by Por, and the released electrons are carried/ transferred by a flavodoxin, which is a likely candidate for a catabolic electron carrier as suggested by its high abundance in our proteome analysis (Table S5). The electrons from the low-potential flavodoxin could either be transferred to menaquinone, or confurcated to QmoABC together with the electrons from the high-potential (disulfide bond) DsrC. QmoABC then reduces menaquinone (Fig. 5), and the electrons are subsequently transferred from QmoABC to the APS reductase (ApsBA) which is, together with three other enzyme complexes (Sat, DsrABD, and DsrMKJOP), responsible for the sulfate reduction cascade [67].

Electron transport from QmoABC to RdhA via menaquinol needs to overcome an energy barrier because electron transport from menaquinol $\left(E^{0,}=-75 \mathrm{mV}\right)$ to the RDase $\left(E^{0},(\mathrm{CoII} / \mathrm{CoI}) \approx-360 \mathrm{mV}\right)$ is thermodynamically unfavorable [10]. However, the protein(s) and process(es) involved to overcome this energy barrier is not clear. One possibility is reverse electron transport as shown for D. vulgaris Hildenborough and D. alaskensis G20 that transfer electrons derived from lactate oxidation through menaquinol to a periplasmic type I cytochrome $c 3$ (TpIc3, $E^{0}=-325$ to $-170 \mathrm{mV}$ ) during syntrophic growth [65]. The energy required for this reverse electron transport is generated by the proton motive force ( $p m f)$ mediated by the Qrc complex [68]. Strain DBB might use a similar strategy to overcome the energy barrier to transfer electrons from menaquinol to the periplasmic RdhA1 (Fig. 5). Qrc was detected in the proteome of DBB cells grown under both LS and LSD conditions (Table S5), whereas the TpIc3 was not identified in the Desulfoluna genomes. Instead of TpIc3, strain DBB could use RdhC1, a homolog to PceC of Dehalobacter restrictus that was proposed to mediate electron transfer from menaquinol to PceA via its exocytoplasmic-facing flavin mononucleotide (FMN) cofactor [16]. Similar to D. restrictus, the RdhC1 of strain DBB contains a conserved FMN binding motif (in particular the fully conserved threonine residue) and two $\mathrm{CX}_{3} \mathrm{CP}$ motifs predicted to have a role in electron transfer [16] (Fig. $\mathrm{S} 11)$. In addition, five transmembrane helices of $\mathrm{RdhC} 1$ in strain DBB are also conserved (Fig. S12), indicating a similar function of $\mathrm{RdhC} 1$ in electron transfer from menaquinones to RdhA1 via FMN co-factor (Fig. 5). However, since $\mathrm{RdhC}$ was not detected in our proteome analysis likely due to tight interactions with the membrane with its five transmembrane helixes, further biochemical studies are necessary to verify the proposed role of $\mathrm{RdhC} 1$ in Desulfoluna OHR.

The $p m f$ derived from sulfate reduction might be used for reverse electron transport during OHR, which may explain accelerated OHR with concurrent sulfate reduction (Fig. S2). Further studies such as construction of Desulfoluna mutant strains lacking qrc genes are necessary to verify the function of Qrc in energy metabolism of Desulfoluna.

\section{Potential oxygen defense in Desulfoluna strains}

Sulfate reducers, which have been assumed to be strictly anaerobic bacteria, not only survive oxygen exposure but can also utilize it as an electron acceptor [69, 70]. However, the response of organohalide-respiring sulfate reducers to oxygen exposure is not known. Most of the described OHRB are strict anaerobes isolated from anoxic and usually organic matter-rich subsurface environments [17]. In contrast, strain DBB was isolated from marine intertidal sediment mainly composed of shore sand (Fig. 1a), where regular exposure to oxic seawater or air can be envisaged. The genomes of the Desulfoluna strains studied here harbor genes encoding enzymes for oxygen reduction and reactive oxygen species (ROS) detoxification (Table S8). Particularly, the presence of a cytochrome $c$ oxidase encoding gene 
is intriguing and may indicate the potential for oxygen respiration. Accordingly, in the presence of $2 \%$ oxygen in the headspace of DBB cultures, the redox indicator resazurin in the medium turned from pink to colorless within two hours, indicating consumption/reduction of oxygen by strain DBB. Growth of strain DBB on lactate and sulfate was retarded in the presence of $2 \%$ oxygen (Fig. S13C). However, in both the presence (Fig. S13C) and absence of sulfate (Fig. S13D), slower but complete debromination of 2,6 -DBP to phenol was achieved with $2 \%$ oxygen in the headspace. Neither growth nor 2,6-DBP debromination was observed with an initial oxygen concentration of $5 \%$ in the headspace (Fig. S13E, F). Such resistance of marine OHRB to oxygen may enable them to occupy niches close to halogenating organisms/enzymes that nearly all use oxygen or peroxides as reactants [71]. For instance, the marine sponge $A$. aerophoba from which $D$. spongiiphila $\mathrm{AA} 1^{\mathrm{T}}$ was isolated [20] harbors bacteria with a variety of $\mathrm{FADH}_{2}{ }^{-}$ dependent halogenases [72], and produces a variety of brominated secondary metabolites [54].

\section{Conclusions}

Widespread environmental contamination with organohalogen compounds and their harmful impacts to human and environmental health has been the driver of chasing OHRB since the 1970s. In addition, the natural environment is an ample and ancient source of organohalogens, and accumulating evidence shows widespread occurrence of putative $r d h A$ in marine environments [6, 24, 73-75]. The previous isolation and description of strain $\mathrm{AAl}^{\mathrm{T}}$ from a marine sponge, the isolation of strain DBB from intertidal sediment samples, and verification of the OHR potential of strain MSL71 ${ }^{\mathrm{T}}$ in this study indicate niche specialization of the members of the genus Desulfoluna as chemoorganotrophic facultative OHRB in marine environments. As such, de novo corrinoid biosynthesis, resistance to sulfate, sulfide and oxygen, versatility in using electron donors, respiration of brominated but not chlorinated aromatic compounds, and the capacity for concurrent sulfate and organohalogen respiration confer an advantage to Desulfoluna strains in marine environments rich in sulfate and organobromines.

Acknowledgements We thank Johanna Gutleben and Maryam Chaib de Mares for sediment sampling, W. Irene C. Rijpstra for fatty acid analysis, and Andreas Marquardt (Proteomics Centre of the University of Konstanz) for proteomic analyses. We acknowledge the China Scholarship Council (CSC) for the support to PP and YL. The authors thank BE-BASIC funds (grants F07.001.05 and F08.004.01) from the Dutch Ministry of Economic Affairs, ERC grant (project 323009), the Gravitation grant (project 024.002.002) and the UNLOCK project (NRGWI.obrug.2018.005) of the Netherlands Ministry of Education, Culture and Science and the Netherlands Science Foundation (NWO), and National Natural Science Foundation of China (project No.51709100) for funding.

\section{Compliance with ethical standards}

Conflict of interest The authors declare that they have no conflict of interest.

Publisher's note Springer Nature remains neutral with regard to jurisdictional claims in published maps and institutional affiliations.

Open Access This article is licensed under a Creative Commons Attribution 4.0 International License, which permits use, sharing, adaptation, distribution and reproduction in any medium or format, as long as you give appropriate credit to the original author(s) and the source, provide a link to the Creative Commons license, and indicate if changes were made. The images or other third party material in this article are included in the article's Creative Commons license, unless indicated otherwise in a credit line to the material. If material is not included in the article's Creative Commons license and your intended use is not permitted by statutory regulation or exceeds the permitted use, you will need to obtain permission directly from the copyright holder. To view a copy of this license, visit http://creativecommons. org/licenses/by/4.0/.

\section{References}

1. Gribble GW. Naturally occurring organohalogen compounds-a comprehensive update. vol 91. Vienna: Springer; 2010.

2. Gribble GW. A recent survey of naturally occurring organohalogen compounds.Environ Chem. 2015;12:396-405.

3. Leri AC, Mayer LM, Thornton KR, Northrup PA, Dunigan MR, Ness KJ, et al. A marine sink for chlorine in natural organic matter. Nat Geosci. 2015;8:620-4.

4. Méndez-Díaz JD, Shimabuku KK, Ma J, Enumah ZO, Pignatello JJ, Mitch WA, et al. Sunlight-driven photochemical halogenation of dissolved organic matter in seawater: a natural abiotic source of organobromine and organoiodine. Environ Sci Technol. 2014; 48:7418-27.

5. Lavric ED, Konnov AA, De Ruyck J. Dioxin levels in wood combustion-a review. Biomass Bioenergy. 2004;26:115-45.

6. Atashgahi S, Häggblom MM, Smidt H. Organohalide respiration in pristine environments: implications for the natural halogen cycle. Environ Microbiol. 2018;20:934-48.

7. Lu Y, Ramiro-Garcia J, Vandermeeren P, Herrmann S, Cichocka $\mathrm{D}$, Springael D, et al. Dechlorination of three tetrachlorobenzene isomers by contaminated harbor sludge-derived enrichment cultures follows thermodynamically favorable reactions. Appl Microbiol Biotechnol. 2017;101:2589-601.

8. Mohn WW, Tiedje JM. Microbial reductive dehalogenation. Microbiol Rev. 1992;56:482-507.

9. Fincker M, Spormann AM. Biochemistry of catabolic reductive dehalogenation. Annu Rev Biochem. 2017;86:357-86.

10. Schubert T, Adrian L, Sawers RG, Diekert G. Organohalide respiratory chains: composition, topology and key enzymes. FEMS Microbiol Ecol. 2018;94:fiy035.

11. Gadkari J, Goris T, Schiffmann CL, Rubick R, Adrian L, Schubert $\mathrm{T}$, et al. Reductive tetrachloroethene dehalogenation in the presence of oxygen by Sulfurospirillum multivorans: physiological studies and proteome analysis. FEMS Microbiol Ecol. 2018;94: fix 176.

12. Kruse T, Smidt H, Lechner U. Comparative genomics and transcriptomics of organohalide-respiring bacteria and regulation of rdh gene transcription. In Adrian L, Löffler FE, editors. 
Organohalide-respiring bacteria. Berlin Heidelberg: Springer; 2016, pp 345-76.

13. Türkowsky D, Jehmlich N, Diekert G, Adrian L, von Bergen M, Goris T. An integrative overview of genomic, transcriptomic and proteomic analyses in organohalide respiration research. FEMS Microbiol Ecol. 2018;94:fiy013.

14. Kublik A, Deobald D, Hartwig S, Schiffmann CL, Andrades A, von Bergen $\mathrm{M}$, et al. Identification of a multi-protein reductive dehalogenase complex in Dehalococcoides mccartyi strain CBDB 1 suggests a protein-dependent respiratory electron transport chain obviating quinone involvement. Environ Microbiol. 2016; 18:3044-56.

15. Futagami T, Goto M, Furukawa K. Genetic system of organohalide-respiring bacteria. In Nojiri H, Tsuda M, Fukuda M, Kamagata Y, editors. Biodegradative bacteria. Japan: Springer; 2014. pp. 59-81.

16. Buttet GF, Willemin MS, Hamelin R, Rupakula A, Maillard J. The membrane-bound $\mathrm{C}$ subunit of reductive dehalogenases: topology analysis and reconstitution of the FMN-binding domain of PceC. Front Microbiol. 2018;9:755.

17. Atashgahi S, Lu Y, Smidt H. Overview of known organohaliderespiring bacteria-phylogenetic diversity and environmental distribution. In Adrian L, Löffler FE, editors. Organohaliderespiring bacteria. Berlin, Germany: Springer; 2016. pp. 63-105.

18. Hug LA, Maphosa F, Leys D, Löffler FE, Smidt H, Edwards EA, et al. Overview of organohalide-respiring bacteria and a proposal for a classification system for reductive dehalogenases. Philos Trans R Soc B. 2013;368:20120322.

19. Futagami T, Morono $\mathrm{Y}$, Terada $\mathrm{T}$, Kaksonen AH, Inagaki $\mathrm{F}$. Dehalogenation activities and distribution of reductive dehalogenase homologous genes in marine subsurface sediments. Appl Environ Microbiol. 2009;75:6905-9.

20. Ahn Y-B, Kerkhof LJ, Häggblom MM. Desulfoluna spongiiphila sp. nov., a dehalogenating bacterium in the Desulfobacteraceae from the marine sponge Aplysina aerophoba. Int J Syst Evol Microbiol. 2009;59:2133-9.

21. Liu J, Lopez N, Ahn YB, Goldberg T, Bromberg Y, Kerkhof LJ, et al. Novel reductive dehalogenases from the marine sponge associated bacterium Desulfoluna spongiiphila. Environ Microbiol Rep. 2017;9:537-49.

22. Sanford RA, Chowdhary J, Löffler FE. Organohalide-respiring Deltaproteobacteria. In Adrian L, Löffler FE, editors. Organohaliderespiring bacteria. Berlin Heidelberg:Springer; 2016. pp. 235-58.

23. Liu J, Häggblom MM. Genome-guided identification of organohalide-respiring Deltaproteobacteria from the marine environment. mBio. 2018;9:e02471-18.

24. Atashgahi S. Discovered by genomics: putative reductive dehalogenases with N-terminus transmembrane helixes. FEMS Microbiol Ecol. 2019;95:fiz048.

25. Jochum LM, Schreiber L, Marshall IP, Jørgensen BB, Schramm A, Kjeldsen KU. Single-cell genomics reveals a diverse metabolic potential of uncultivated Desulfatiglans-related Deltaproteobacteria widely distributed in marine sediment. Front Microbiol. 2018;9:2038.

26. Adrian L, Hansen SK, Fung JM, Görisch H, Zinder SH. Growth of Dehalococcoides strains with chlorophenols as electron acceptors. Environ Sci Technol. 2007;41:2318-23.

27. May HD, Miller GS, Kjellerup BV, Sowers KR. Dehalorespiration with polychlorinated biphenyls by an anaerobic ultramicrobacterium. Appl Environ Microbiol. 2008;74:2089-94.

28. He J, Sung Y, Krajmalnik-Brown R, Ritalahti KM, Löffler FE. Isolation and characterization of Dehalococcoides sp. strain FL2, a trichloroethene (TCE)-and 1,2-dichloroethene-respiring anaerobe. Environ Microbiol. 2005;7:1442-50.

29. Mao X, Polasko A, Alvarez-Cohen L. The effects of sulfate reduction on trichloroethene dechlorination by Dehalococcoides- containing microbial communities. Appl Environ Microbiol. 2017;83:e03384-16

30. Townsend GT, Suflita JM. Influence of sulfur oxyanions on reductive dehalogenation activities in Desulfomonile tiedjei. Appl Environ Microbiol. 1997;63:3594-9.

31. Ahn Y-B, Rhee S-K, Fennell DE, Kerkhof LJ, Hentschel U, Häggblom MM. Reductive dehalogenation of brominated phenolic compounds by microorganisms associated with the marine sponge Aplysina aerophoba. Appl Environ Microbiol. 2003; 69:4159-66.

32. Suzuki D, Ueki A, Amaishi A, Ueki K. Desulfoluna butyratoxydans gen. nov., sp. nov., a novel Gram-negative, butyrate-oxidizing, sulfate-reducing bacterium isolated from an estuarine sediment in Japan. Int J Syst Evol Microbiol. 2008;58:826-32.

33. Monserrate E, Häggblom M. Dehalogenation and biodegradation of brominated phenols and benzoic acids under iron-reducing, sulfidogenic, and methanogenic conditions. Appl Environ Microbiol. 1997;63:3911-5.

34. Stams AJ, Van Dijk JB, Dijkema C, Plugge CM. Growth of syntrophic propionate-oxidizing bacteria with fumarate in the absence of methanogenic bacteria. Appl Environ Microbiol. 1993;59:1114-9.

35. Atashgahi S, Lu Y, Zheng Y, Saccenti E, Suarez-Diez M, RamiroGarcia J, et al. Geochemical and microbial community determinants of reductive dechlorination at a site biostimulated with glycerol. Environ Microbiol. 2017;19:968-81.

36. Ramiro-Garcia J, Hermes GD, Giatsis C, Sipkema D, Zoetendal EG, Schaap PJ, et al. NG-Tax, a highly accurate and validated pipeline for analysis of 16S rRNA amplicons from complex biomes. F1000Research. 2016;5:1791.

37. Edgar RC. Search and clustering orders of magnitude faster than BLAST. Bioinformatics. 2010;26:2460-1.

38. Quast C, Pruesse E, Yilmaz P, Gerken J, Schweer T, Yarza P, et al. The SILVA ribosomal RNA gene database project: improved data processing and web-based tools. Nucleic Acids Res. 2012;41:D590-D596.

39. Caporaso JG, Kuczynski J, Stombaugh J, Bittinger K, Bushman FD, Costello EK, et al. QIIME allows analysis of highthroughput community sequencing data. Nat Methods. 2010; $7: 335-6$.

40. Chikhi R, Medvedev P. Informed and automated k-mer size selection for genome assembly. Bioinformatics. 2013;30:31-7.

41. Bankevich A, Nurk S, Antipov D, Gurevich AA, Dvorkin M, Kulikov AS, et al. SPAdes: a new genome assembly algorithm and its applications to single-cell sequencing. J Comput Biol. 2012;19:455-77.

42. Chakraborty M, Baldwin-Brown JG, Long AD, Emerson J. Contiguous and accurate de novo assembly of metazoan genomes with modest long read coverage. Nucleic Acids Res. 2016;44: e147.

43. Camacho C, Coulouris G, Avagyan V, Ma N, Papadopoulos J, Bealer $\mathrm{K}$, et al. BLAST+: architecture and applications. BMC Bioinforma. 2009;10:421.

44. Walker BJ, Abeel T, Shea T, Priest M, Abouelliel A, Sakthikumar $\mathrm{S}$, et al. Pilon: an integrated tool for comprehensive microbial variant detection and genome assembly improvement. PLoS One. 2014;9:e112963.

45. Bolger AM, Lohse M, Usadel B. Trimmomatic: a flexible trimmer for Illumina sequence data. Bioinformatics. 2014;30:2114-20.

46. Langmead B, Salzberg SL. Fast gapped-read alignment with Bowtie 2. Nat Methods. 2012;9:357-9.

47. Li H, Handsaker B, Wysoker A, Fennell T, Ruan J, Homer N, et al. The sequence alignment/map format and SAMtools. Bioinformatics. 2009;25:2078-9.

48. Peng P, Zheng Y, Koehorst JJ, Schaap PJ, Stams AJ, Smidt H, et al. Concurrent haloalkanoate degradation and chlorate reduction 
by Pseudomonas chloritidismutans $\mathrm{AW}-1^{\mathrm{T}}$. Appl Environ Microbiol. 2017;83:00325-17.

49. Bradford MM. A rapid and sensitive method for the quantitation of microgram quantities of protein utilizing the principle of protein-dye binding. Anal Biochem. 1976;72:248-54.

50. Burrichter A, Denger K, Franchini P, Huhn T, Müller N, Spiteller $\mathrm{D}$, et al. Anaerobic degradation of the plant sugar sulfoquinovose concomitant with $\mathrm{H}_{2} \mathrm{~S}$ production: Escherichia coli $\mathrm{K}-12$ and Desulfovibrio sp. strain DF1 as co-culture model. Front Microbiol. 2018;9:2792.

51. Wieczorek S, Combes F, Lazar C, Giai Gianetto Q, Gatto L, Dorffer A, et al. DAPAR \& ProStaR: software to perform statistical analyses in quantitative discovery proteomics. Bioinformatics. 2017;33:135-6.

52. Cline JD. Spectrophotometric determination of hydrogen sulfide in natural waters. Limnol Oceanogr. 1969;14:454-8.

53. Wagner A, Cooper M, Ferdi S, Seifert J, Adrian L. Growth of Dehalococcoides mccartyi strain CBDB1 by reductive dehalogenation of brominated benzenes to benzene. Environ Sci Technol. 2012;46:8960-8.

54. Turon X, Becerro MA, Uriz MJ. Distribution of brominated compounds within the sponge Aplysina aerophoba: coupling of $\mathrm{X}$-ray microanalysis with cryofixation techniques. Cell Tissue Res. 2000;301:311-22.

55. Richter M, Rosselló-Móra R. Shifting the genomic gold standard for the prokaryotic species definition. Proc Natl Acad Sci USA. 2009;106:19126-31.

56. Smidt H, de Vos WM. Anaerobic microbial dehalogenation. Annu Rev Microbiol. 2004;58:43-73.

57. Lu Y, Atashgahi S, Hug LA, Smidt H. Primers that target functional genes of organohalide-respiring bacteria. In McGenity TJ, Timmis KN, Nogales B, editors. Hydrocarbon and lipid microbiology protocols. Berlin, Heidelberg: Springer; 2015. pp. 177-205.

58. Goris T, Schiffmann CL, Gadkari J, Schubert T, Seifert J, Jehmlich $\mathrm{N}$, et al. Proteomics of the organohalide-respiring Epsilonproteobacterium Sulfurospirillum multivorans adapted to tetrachloroethene and other energy substrates. Sci Rep. 2015;5:13794.

59. Finneran KT, Forbush HM, VanPraagh CVG, Lovley DR. Desulfitobacterium metallireducens sp. nov., an anaerobic bacterium that couples growth to the reduction of metals and humic acids as well as chlorinated compounds. Int J Syst Evol Microbiol. 2002;52:1929-35.

60. Kruse T, Goris T, Maillard J, Woyke T, Lechner U, de Vos W, et al. Comparative genomics of the genus Desulfitobacterium. FEMS Microbiol Ecol. 2017;93:fix135.

61. Zanaroli G, Negroni A, Häggblom MM, Fava F. Microbial dehalogenation of organohalides in marine and estuarine environments. Curr Opin Biotechnol. 2015;33:287-95.
62. Weatherill JJ, Atashgahi S, Schneidewind U, Krause S, Ullah S, Cassidy N, et al. Natural attenuation of chlorinated ethenes in hyporheic zones: a review of key biogeochemical processes and in-situ transformation potential. Water Res. 2018;128:362-82.

63. DeWeerd KA, Suflita JM. Anaerobic aryl reductive dehalogenation of halobenzoates by cell extracts of "Desulfomonile tiedjei". Appl Environ Microbiol. 1990;56:2999-3005.

64. Caffrey SM, Voordouw G. Effect of sulfide on growth physiology and gene expression of Desulfovibrio vulgaris Hildenborough. Antonie Van Leeuwenhoek. 2010;97:11-20.

65. Meyer B, Kuehl J, Deutschbauer AM, Price MN, Arkin AP, Stahl DA. Variation among Desulfovibrio species in electron transfer systems used for syntrophic growth. J Bacteriol. 2013;195:990-1004.

66. Vita N, Valette O, Brasseur G, Lignon S, Denis Y, Ansaldi M, et al. The primary pathway for lactate oxidation in Desulfovibrio vulgaris. Front Microbiol. 2015;6:606.

67. Santos AA, Venceslau SS, Grein F, Leavitt WD, Dahl C, Johnston DT, et al. A protein trisulfide couples dissimilatory sulfate reduction to energy conservation. Science. 2015;350:1541-5.

68. Duarte AG, Catarino T, White GF, Lousa D, Neukirchen S, Soares CM, et al. An electrogenic redox loop in sulfate reduction reveals a likely widespread mechanism of energy conservation. Nat Commun. 2018;9:5448.

69. Dolla A, Fournier M, Dermoun Z. Oxygen defense in sulfatereducing bacteria. J Biotechnol. 2006;126:87-100.

70. Fournier M, Zhang Y, Wildschut JD, Dolla A, Voordouw JK, Schriemer DC, et al. Function of oxygen resistance proteins in the anaerobic, sulfate-reducing bacterium Desulfovibrio vulgaris Hildenborough. J Bacteriol. 2003;185:71-9.

71. Field JA. Natural production of organohalide compounds in the environment. In Adrian L, Löffler FE, editors. Organohaliderespiring bacteria. Berlin, Heidelberg: Springer; 2016. pp. 7-29.

72. Bayer K, Scheuermayer M, Fieseler L, Hentschel U. Genomic mining for novel FADH2-dependent halogenases in marine sponge-associated microbial consortia. Mar Biotechnol. 2013;15:63-72.

73. Spang A, Stairs CW, Dombrowski N, Eme L, Lombard J, Caceres $\mathrm{EF}$, et al. Proposal of the reverse flow model for the origin of the eukaryotic cell based on comparative analyses of Asgard archaeal metabolism. Nat Microbiol. 2019;4:1138-48.

74. Dong X, Greening C, Rattray JE, Chakraborty A, Chuvochina M, Mayumi D, et al. Metabolic potential of uncultured bacteria and archaea associated with petroleum seepage in deep-sea sediments. Nat Commun. 2019;10:1816.

75. Manoharan L, Kozlowski JA, Murdoch RW, Löffler FE, Sousa FL, Schleper C. Metagenomes from coastal marine sediments give insights into the ecological role and cellular features of Loki- and Thorarchaeota. mBio. 2019;10:e2039-19. 